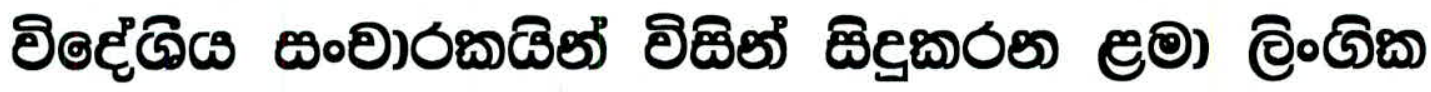

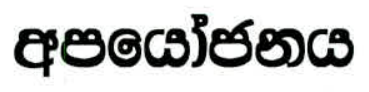

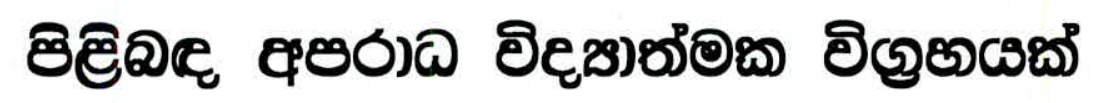

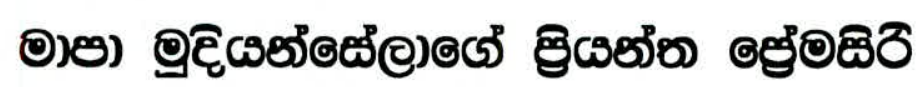

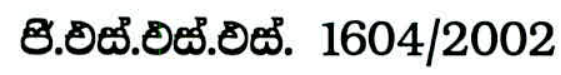

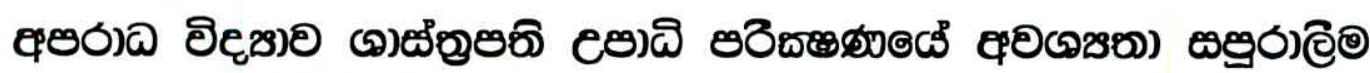

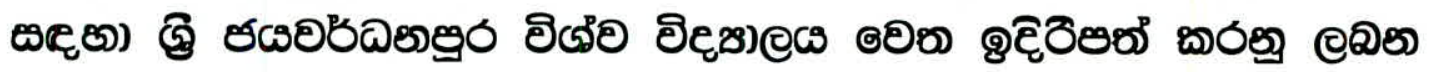

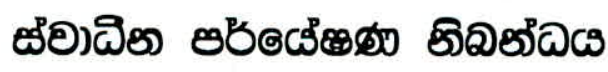




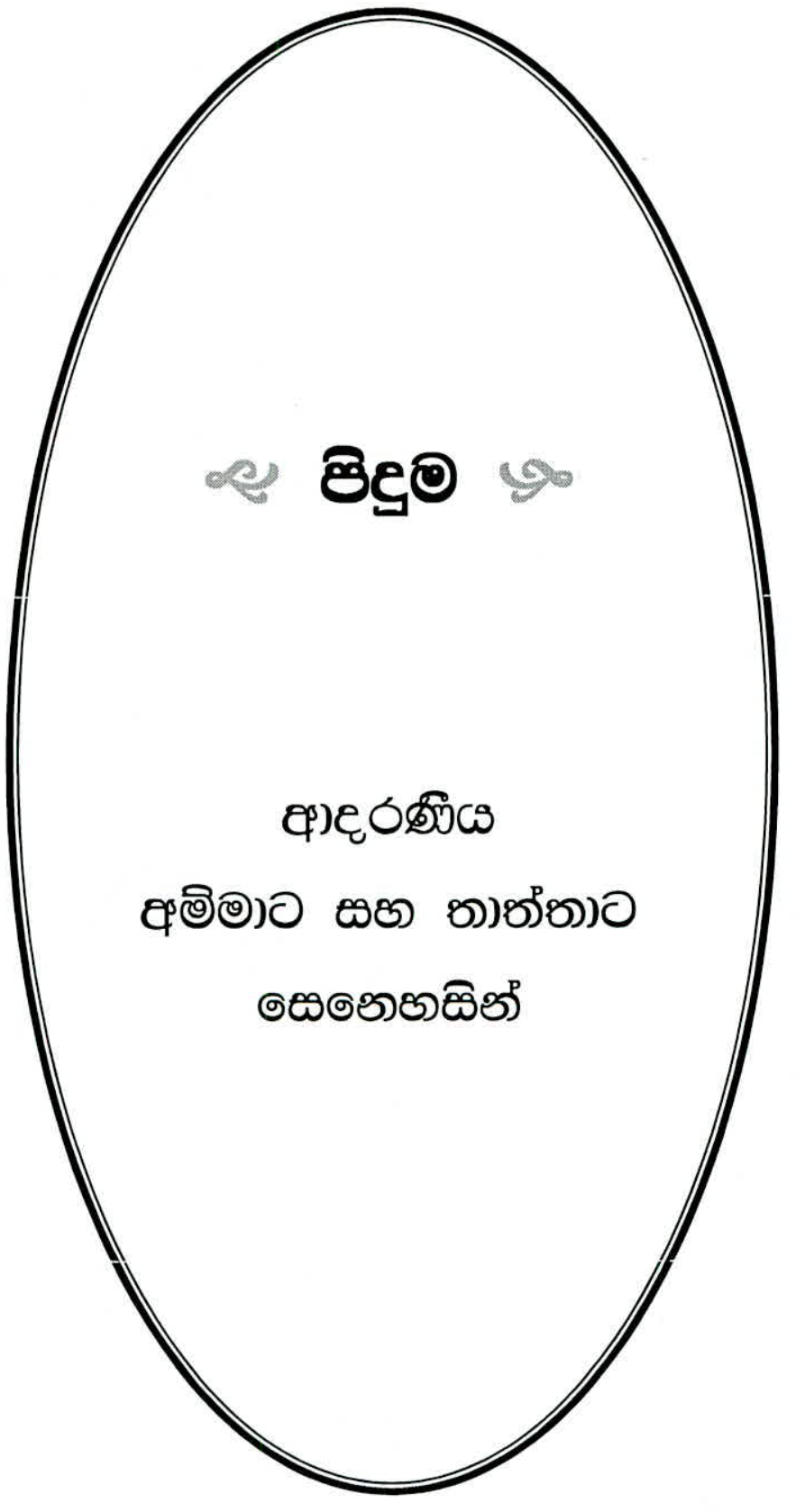




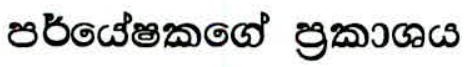

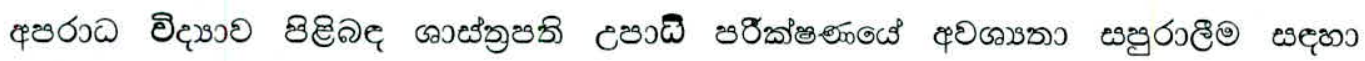

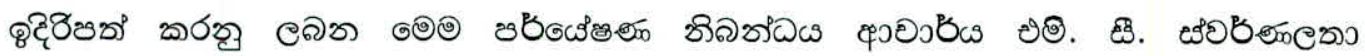

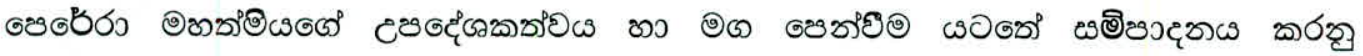

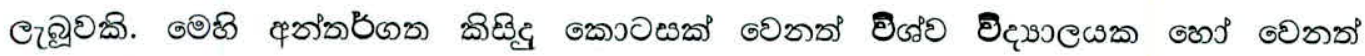

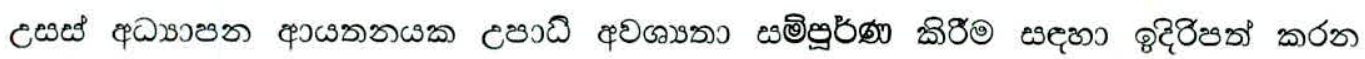

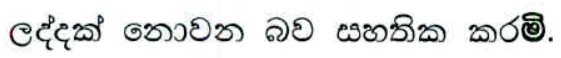

$2007: 03: 22$

दृळ

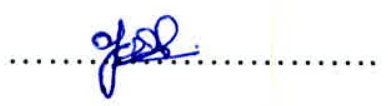

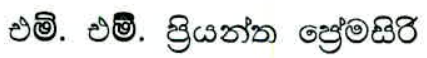

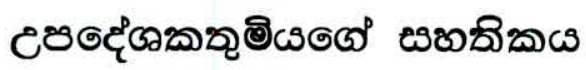

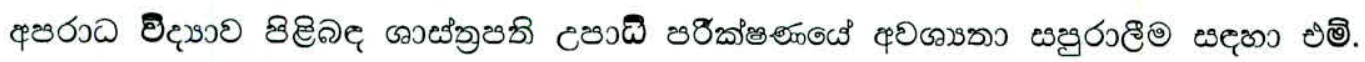

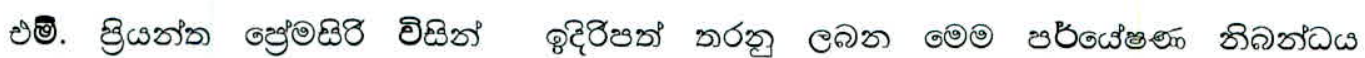

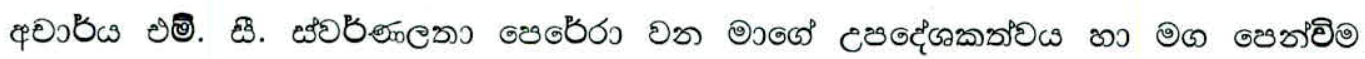

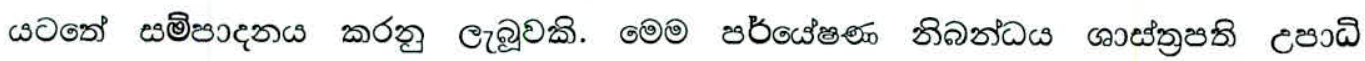

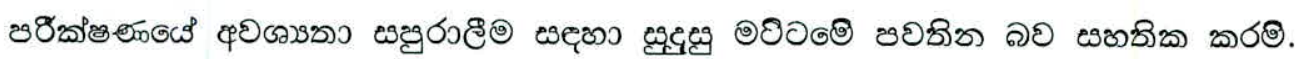

\section{$22.03 \cdot 2007$}

दृखा

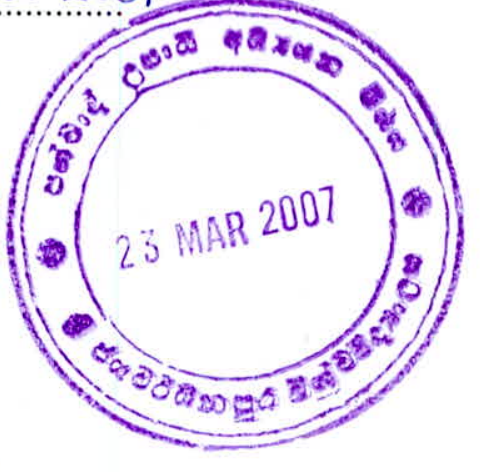

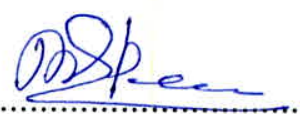

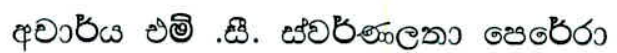

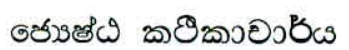




\section{ఱீఐణిద}

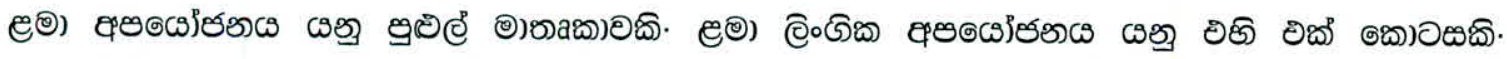

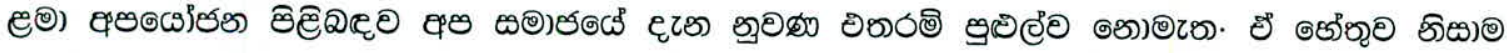

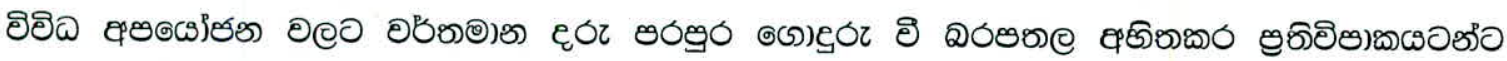

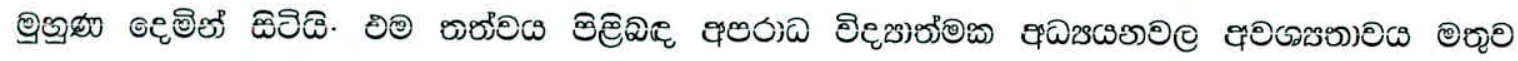

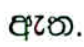

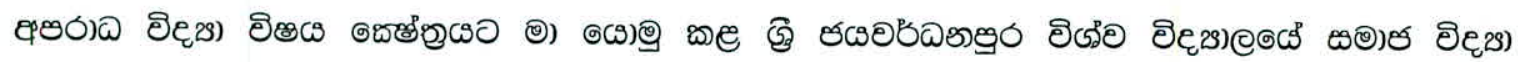

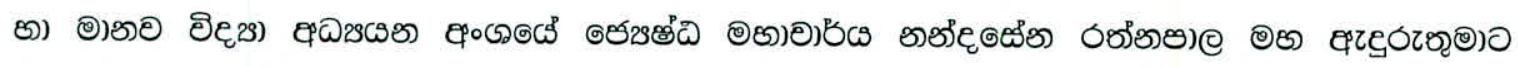

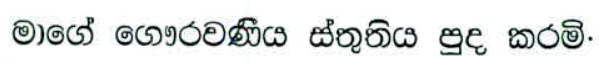

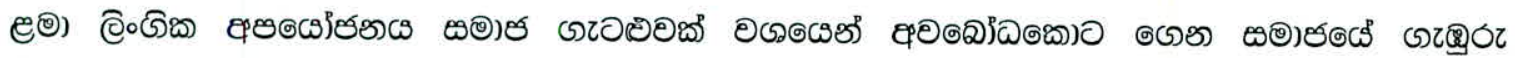

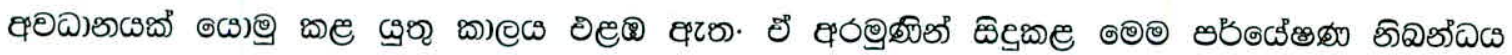

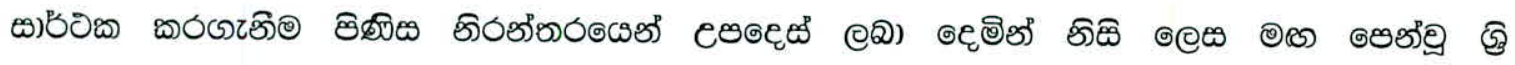

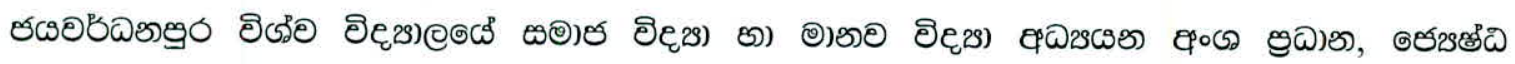

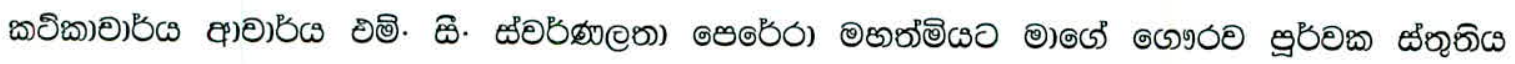
అூరి దుంతి.

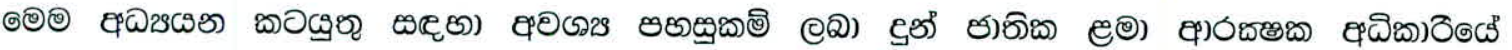

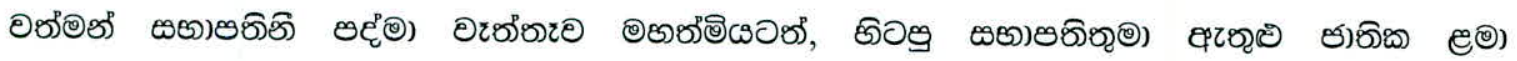

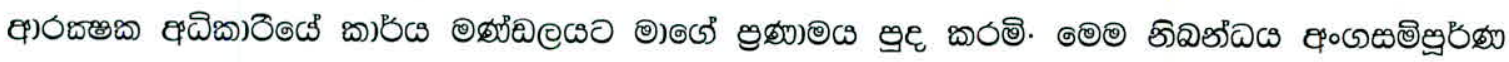

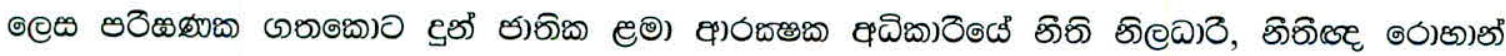

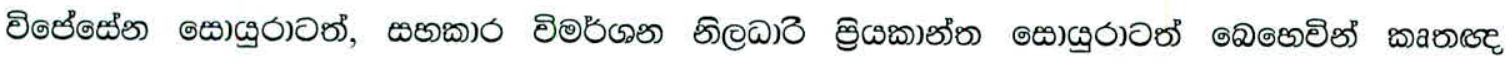
๔อతి. 


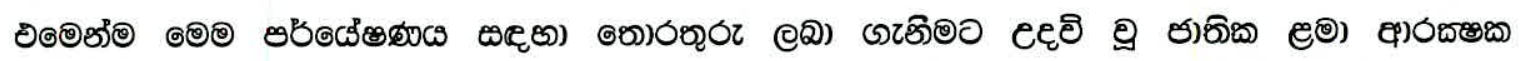

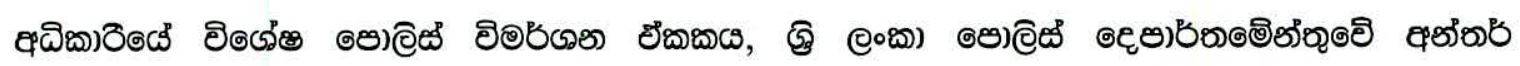

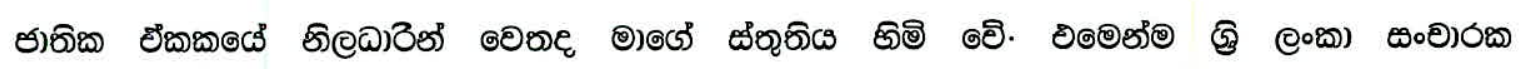

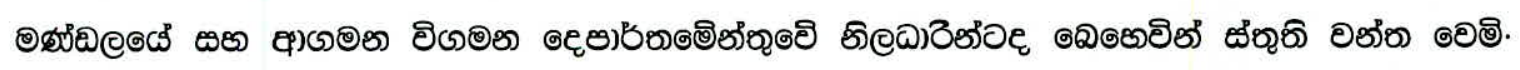

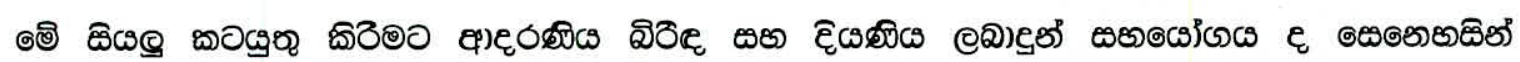
డికిఅరో దుతి. 


\section{అఱ్ర అరెలితరైడి}

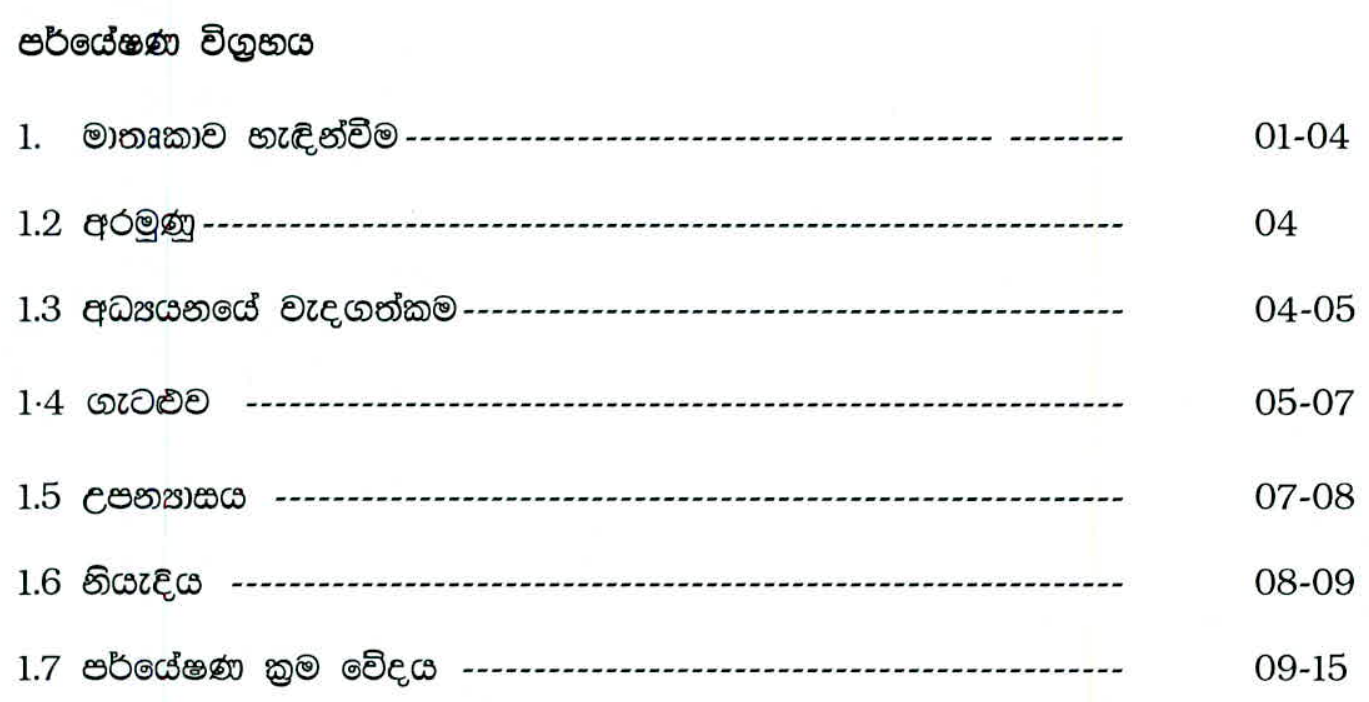

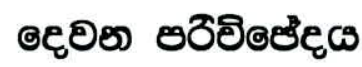

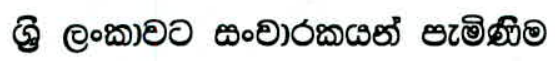

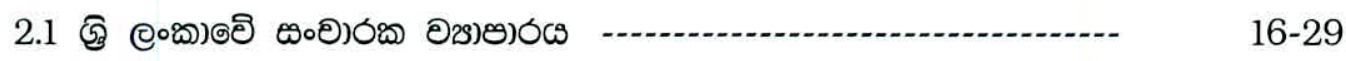

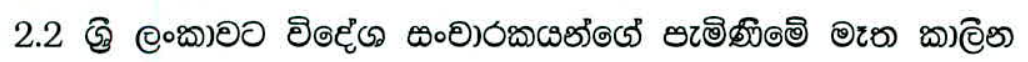

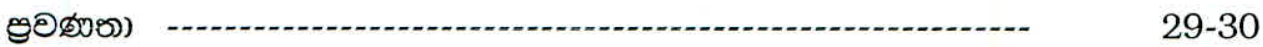

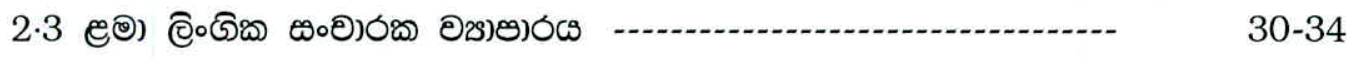

\section{ఆరిలి అరెలితారెడిడ}

ம.దాలెడి లిన్రకు

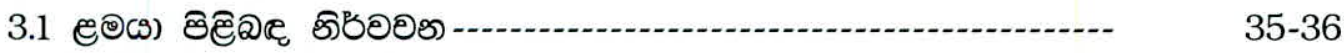

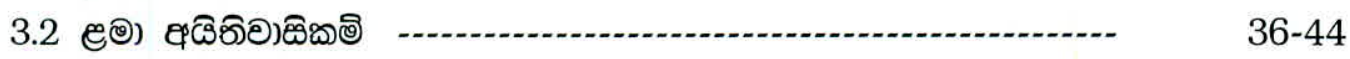

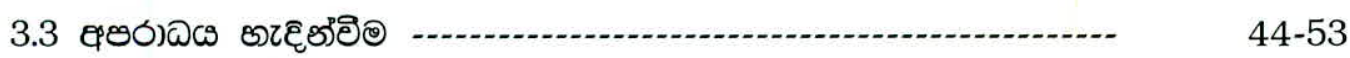




\section{డిలిలె అరెలితరికెడ}

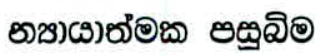

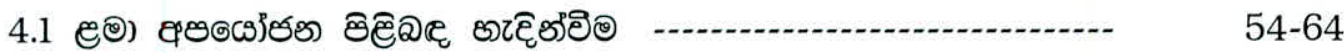

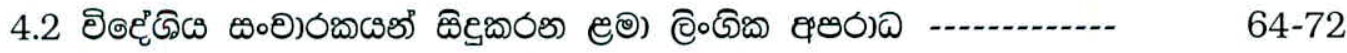

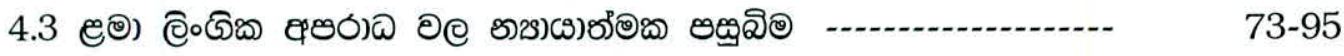

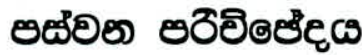

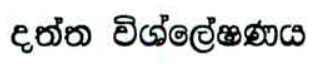

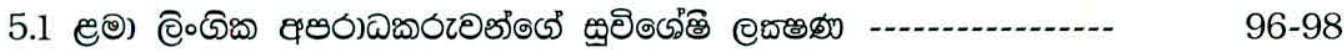

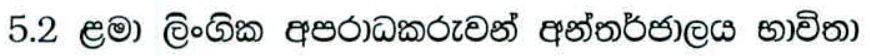

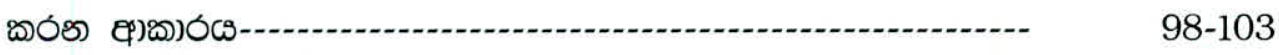

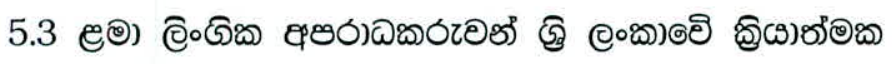

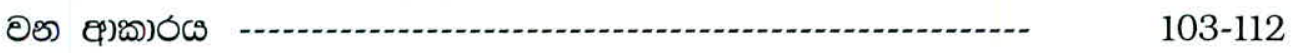

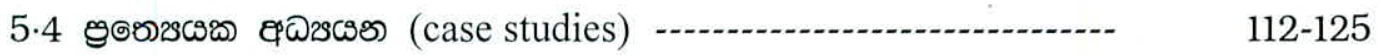

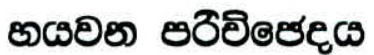

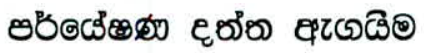

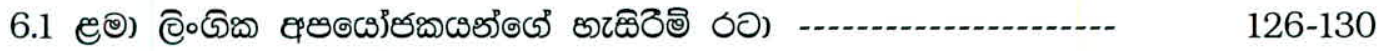

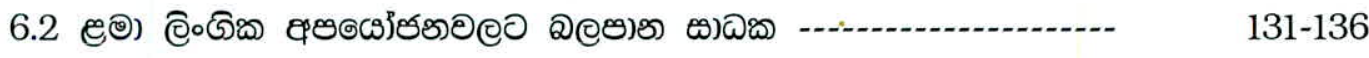

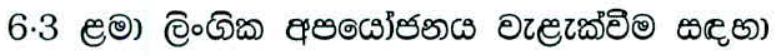

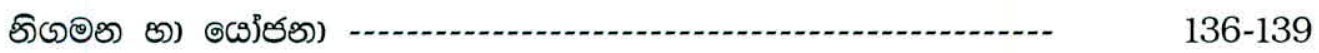

\section{థార్త్రితి}

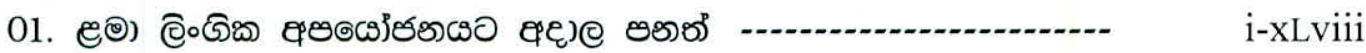

02. 182 Worst Form of Child Labour Convention, 1999 -------- $\quad$ xLix-Lv

03. Convention on the Right of Child - - Lxvi-Lvii 
04. Optional Protocol to the Convention on the on the right of the child on the sale of Children, Child Prostitution and Pornography Lviii-LXv

05. A National Coordination Mechanism: The National Child Protection Authority Lxvi-Lxxix

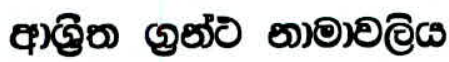




\section{అల్త అరెలిఠరైడడ}

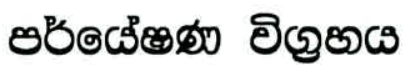

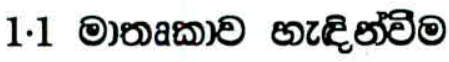

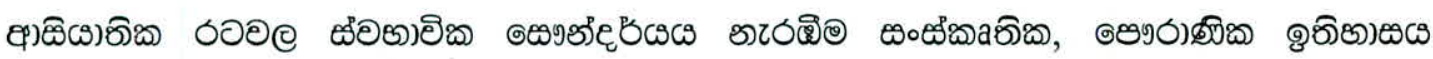

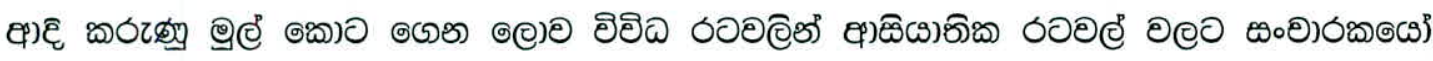

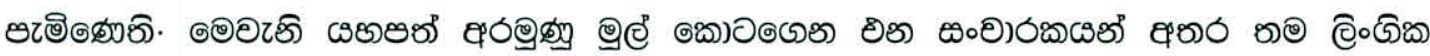

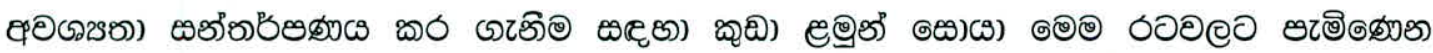

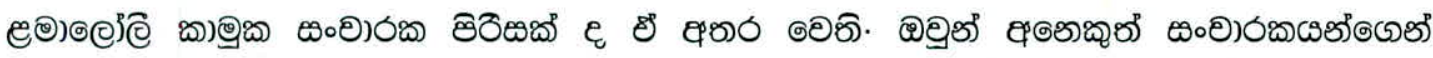

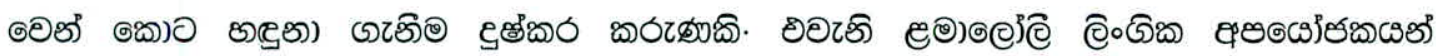

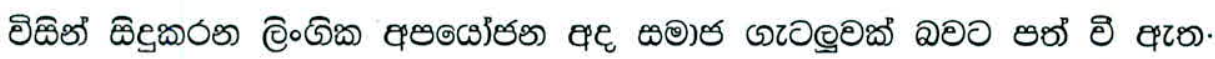

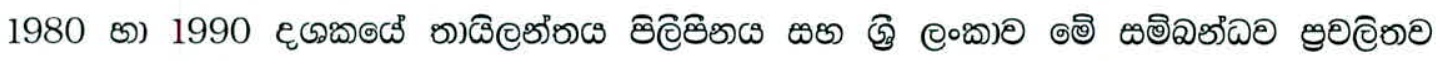

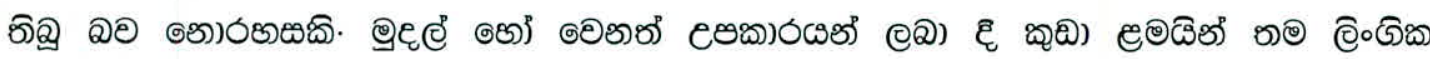

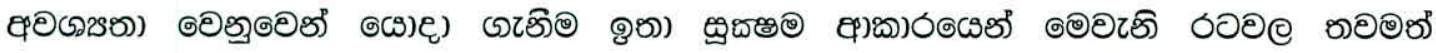

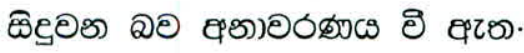

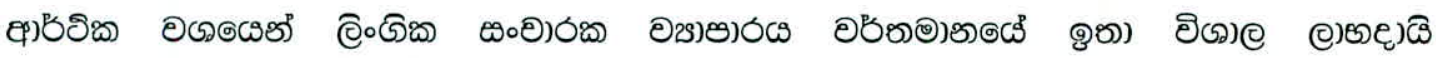

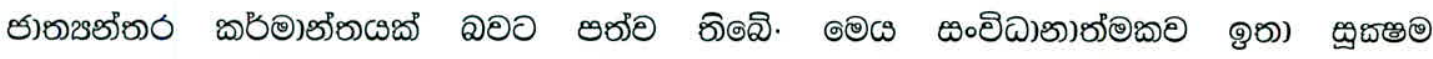

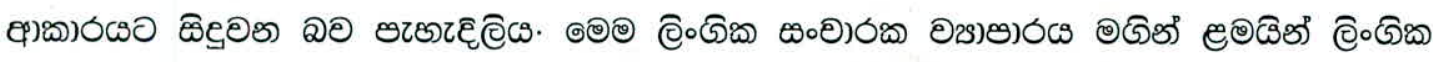

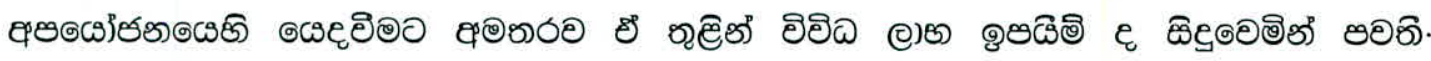

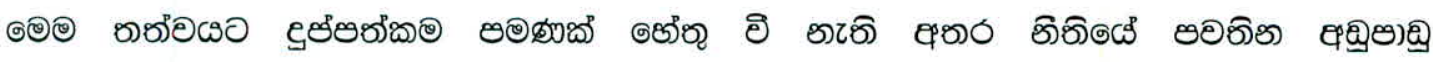

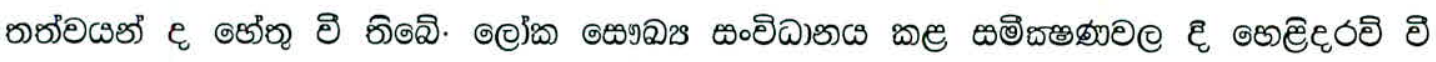

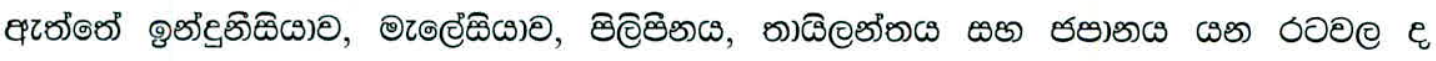




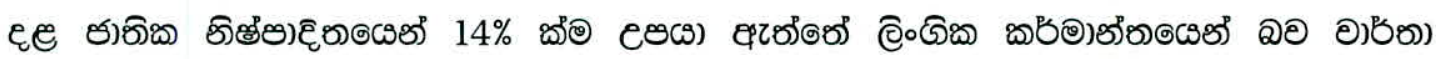

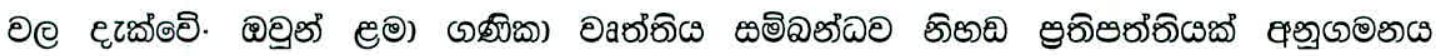

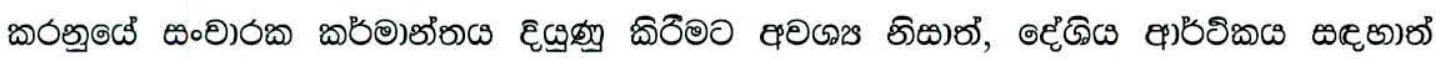

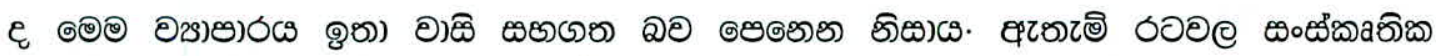

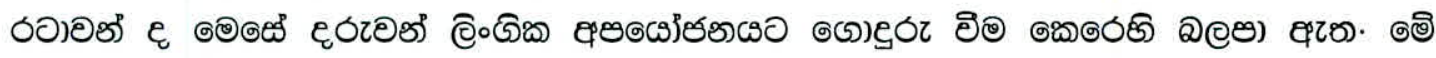

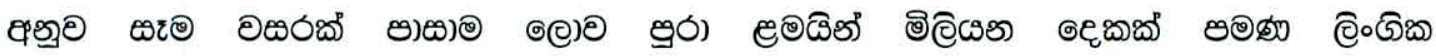

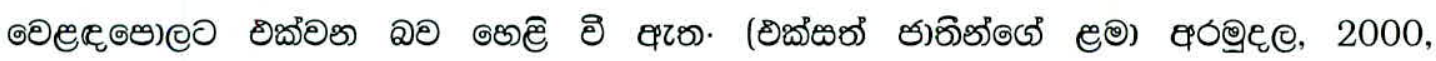
2001)

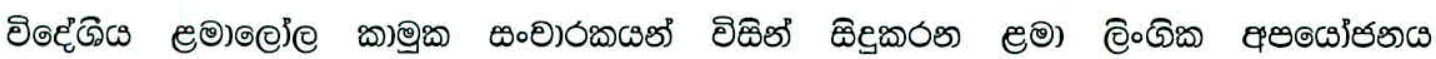
తిలెఎణ్

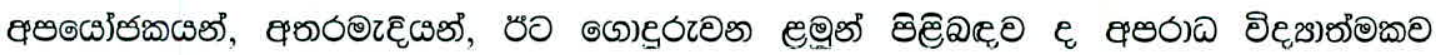

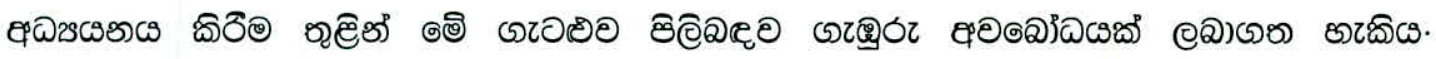

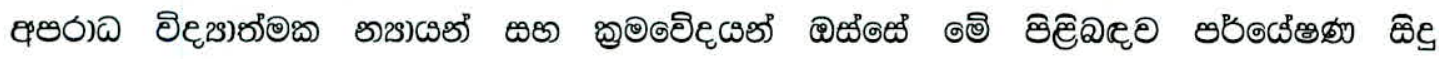

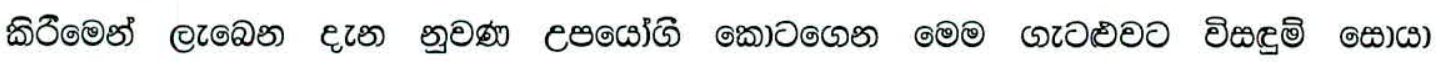

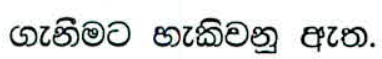

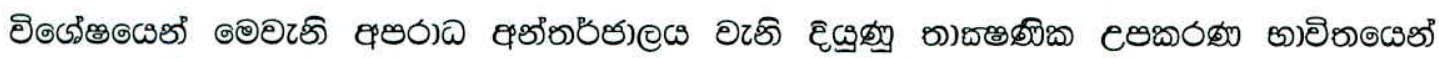

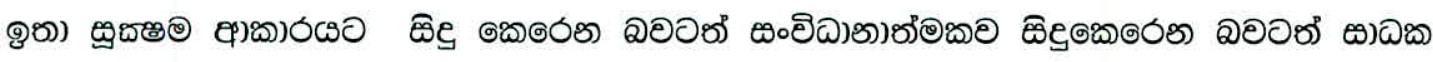

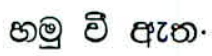

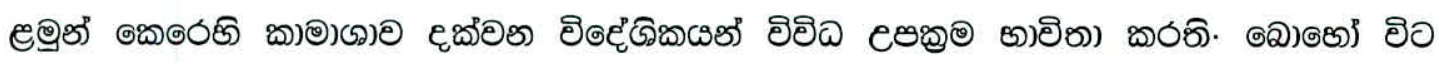

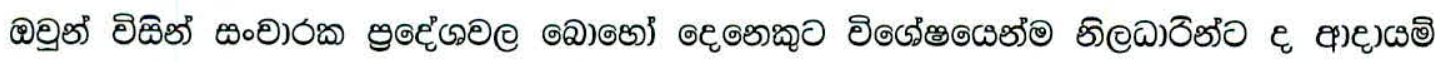

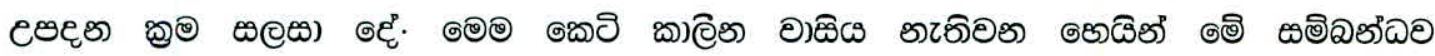

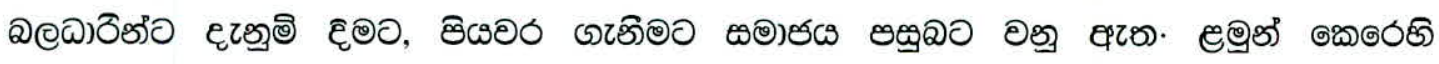

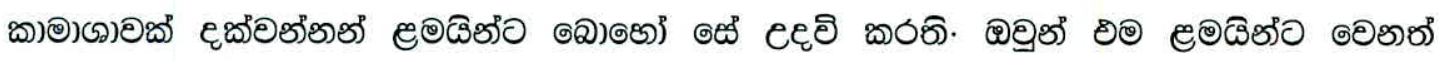




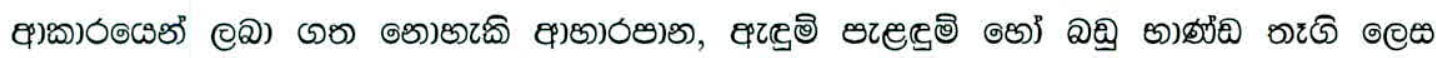

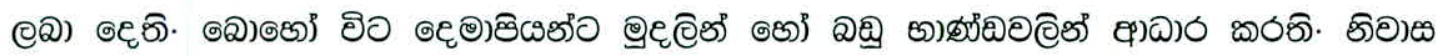

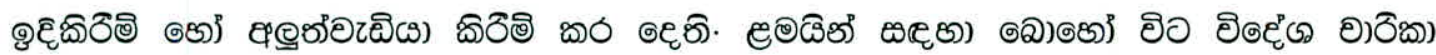

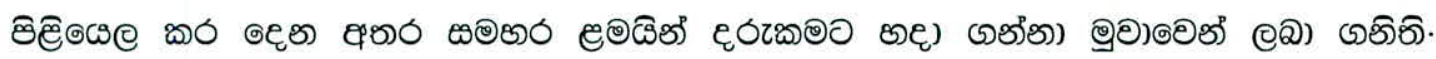

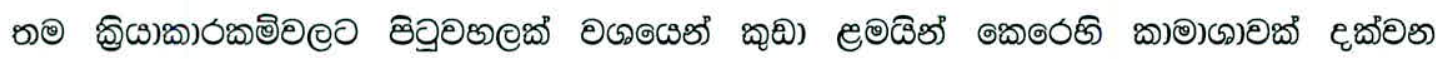

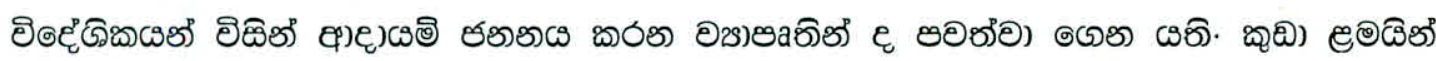

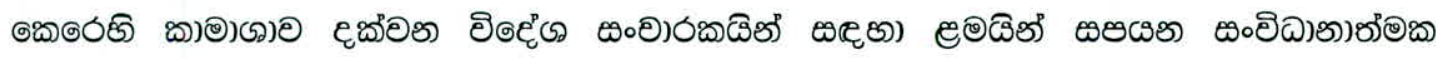

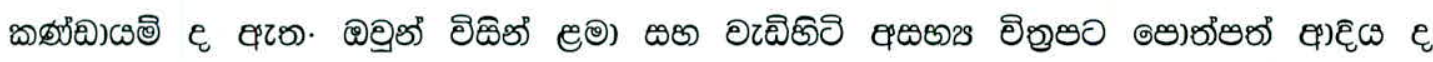

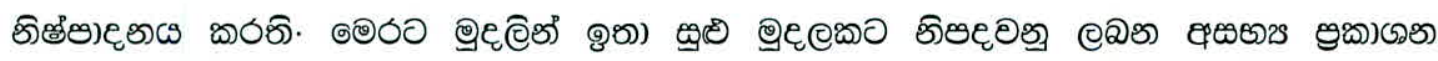

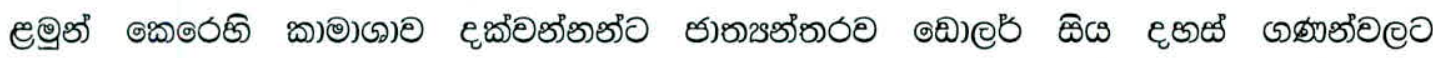

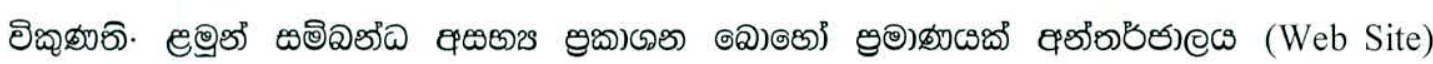

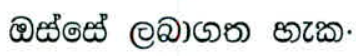

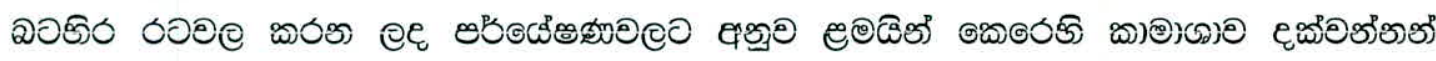

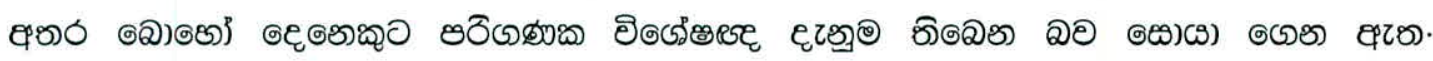

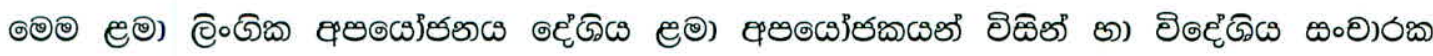

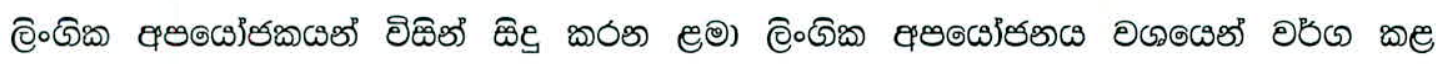
काळิต.

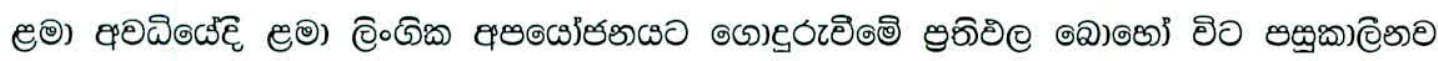

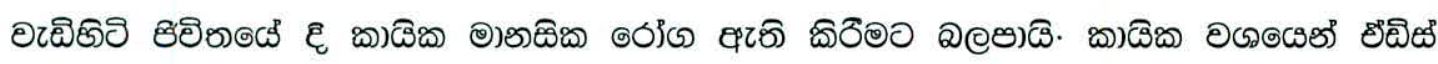

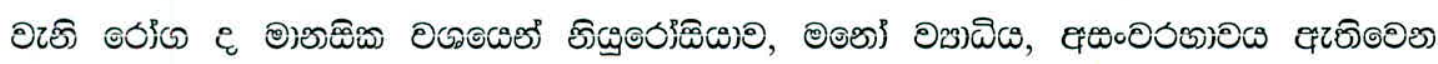

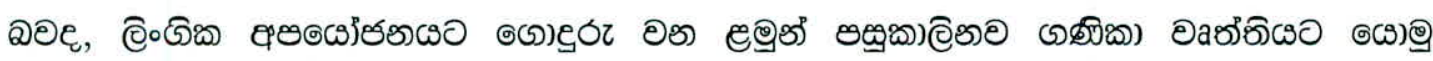

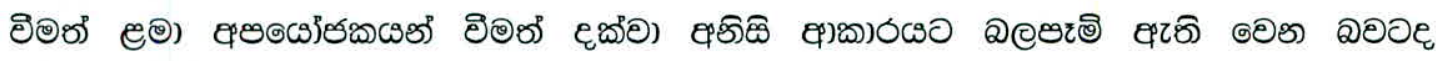

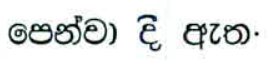




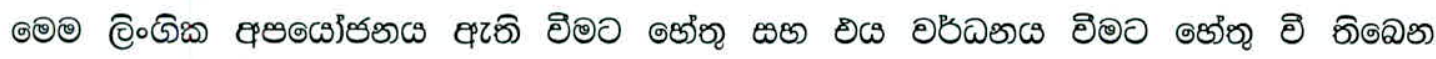

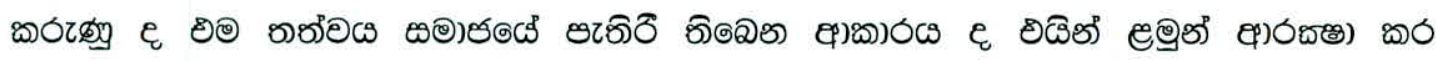

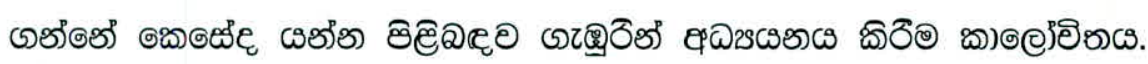

\section{2 ๕ార@}

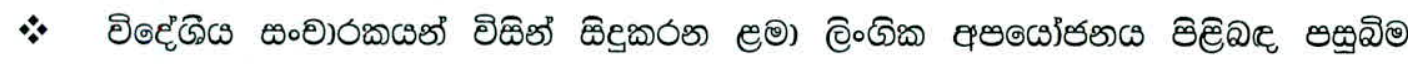
ออย) ตรื่อ.

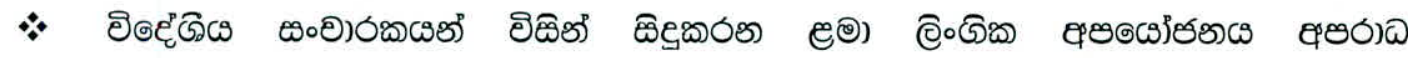

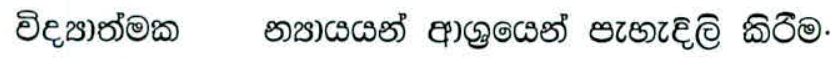

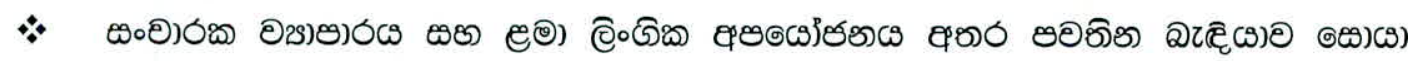
இrอెఠ.

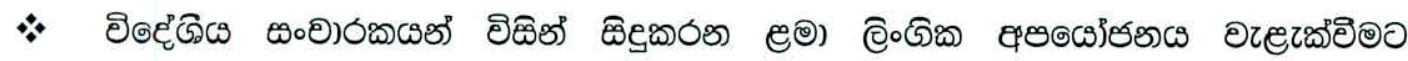

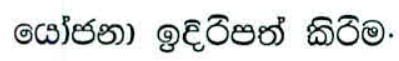

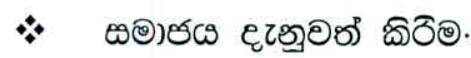

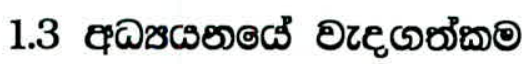

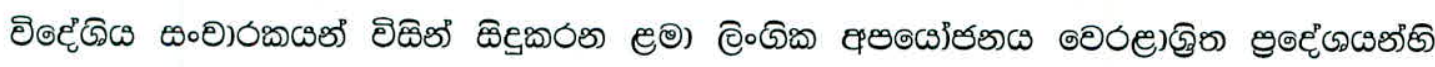

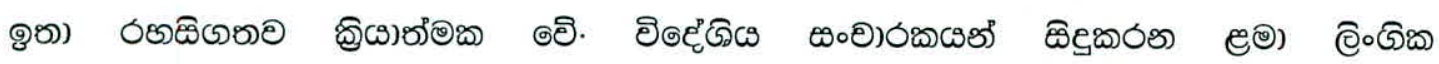

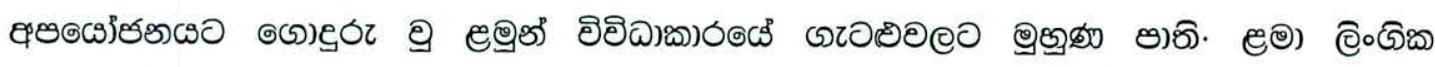

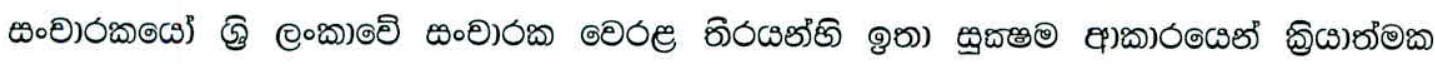

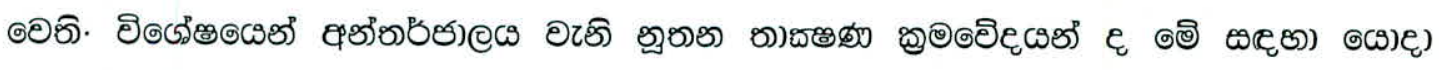

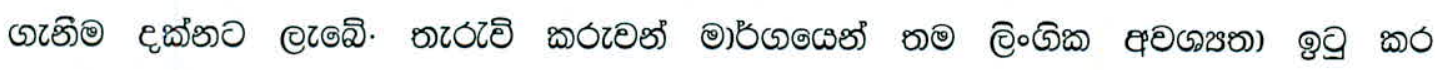

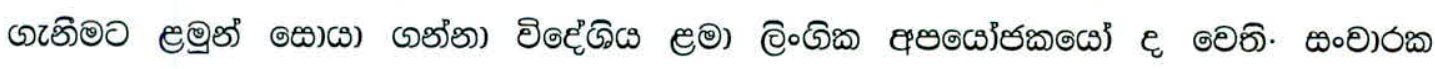

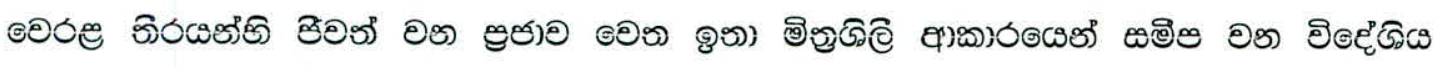

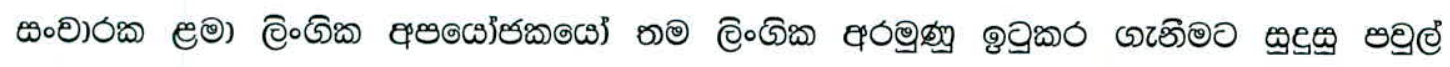




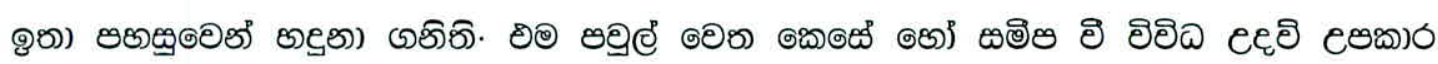

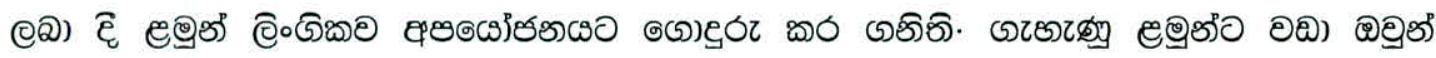

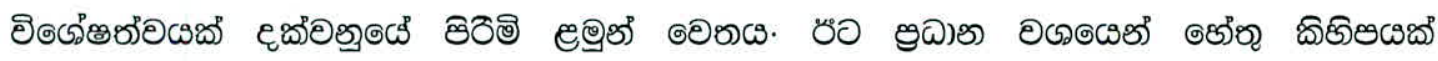

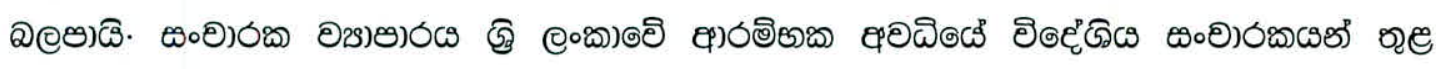

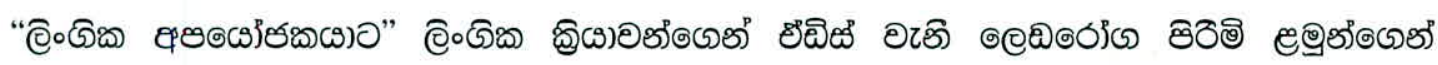

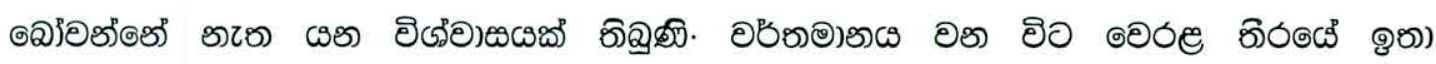

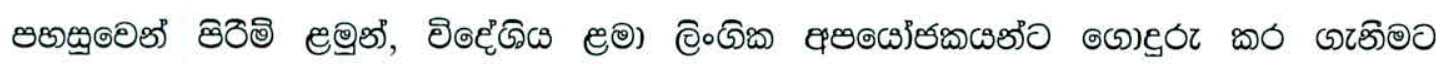

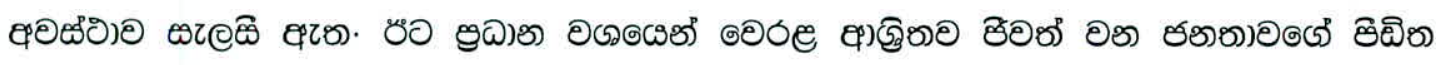

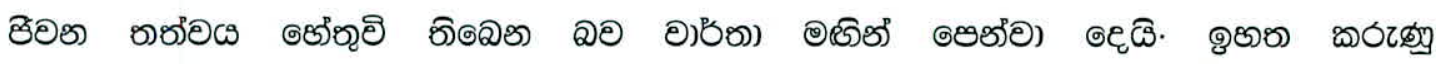

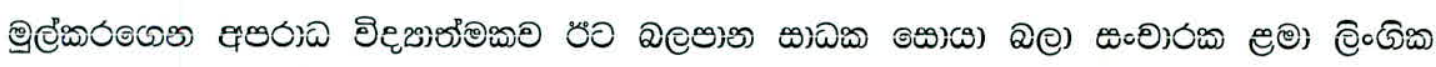

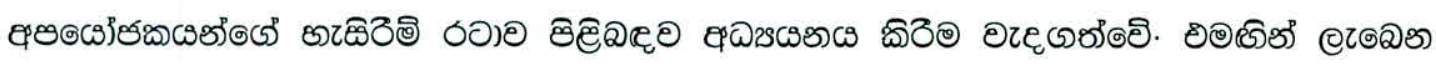

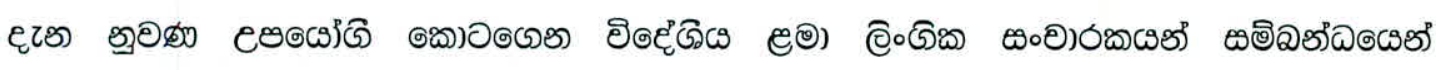

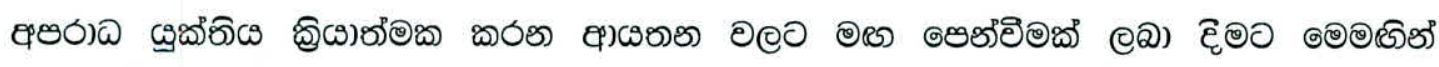

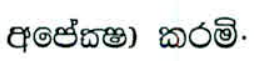

\section{4 ตrอ®อ}

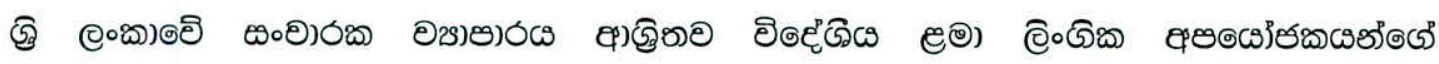

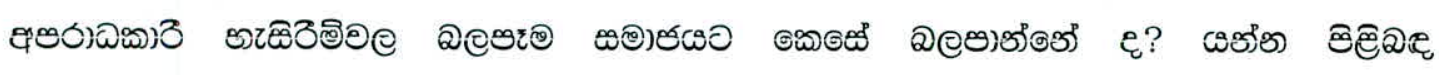

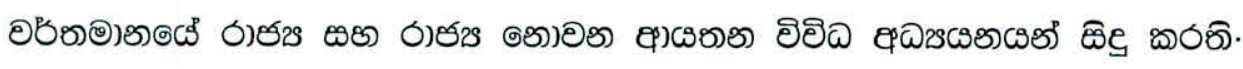

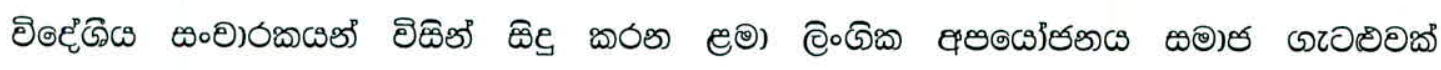

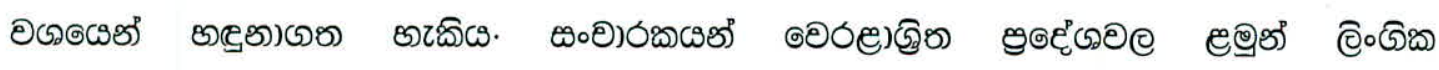

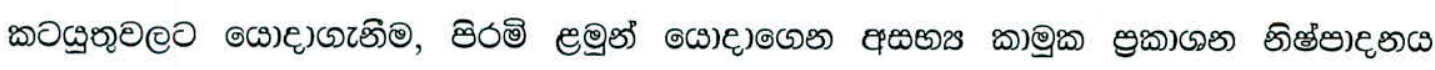

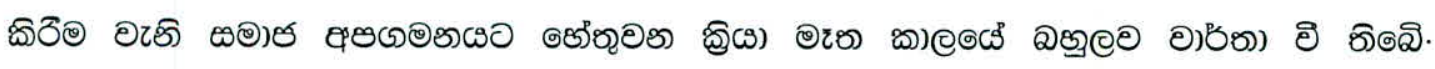

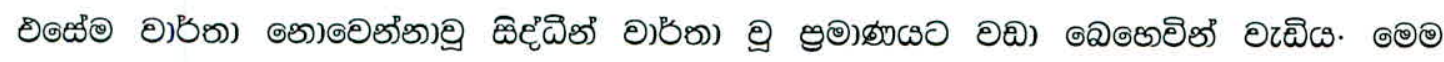




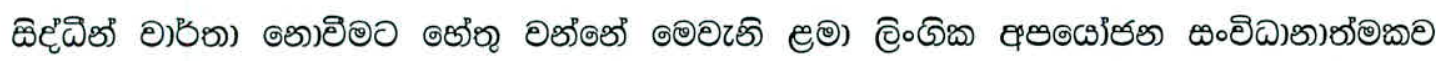

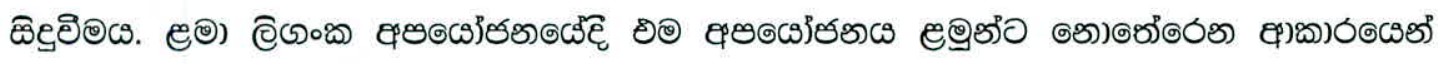

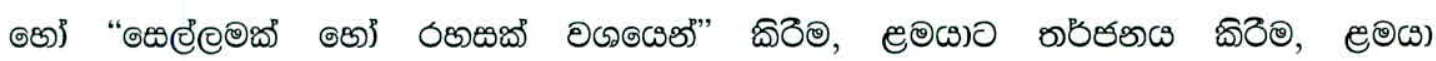

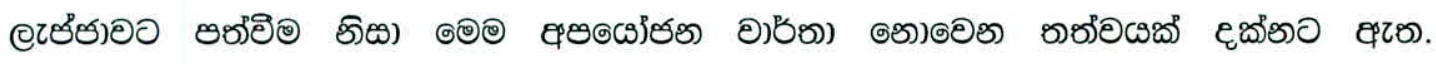

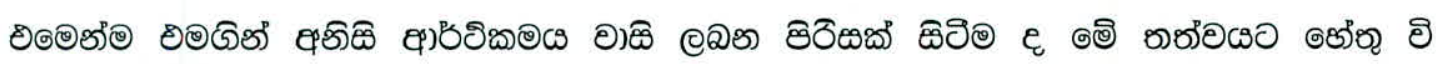

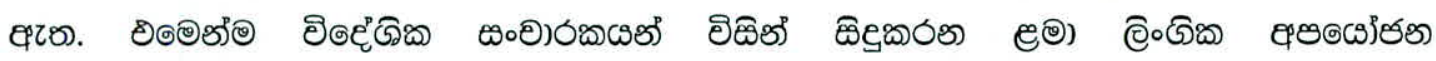

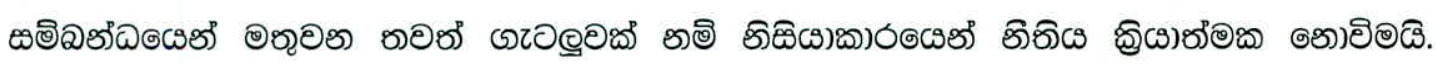

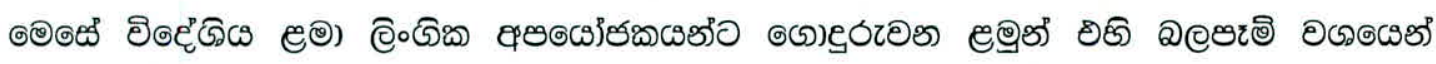

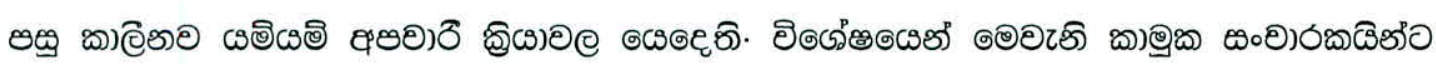

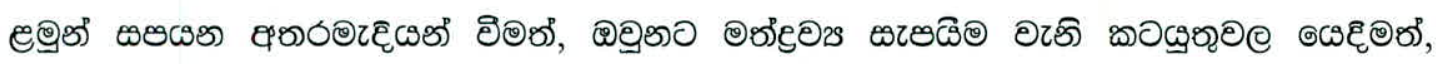

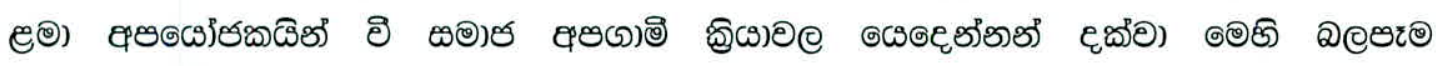

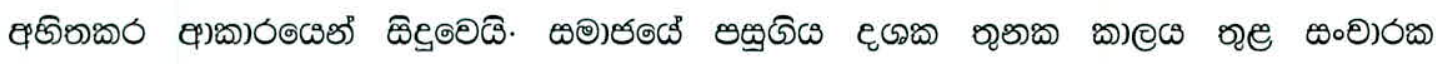

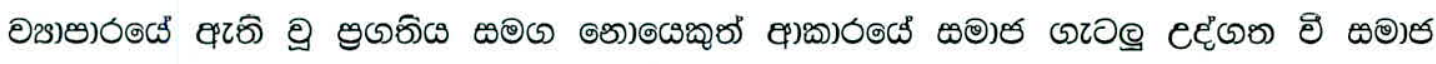

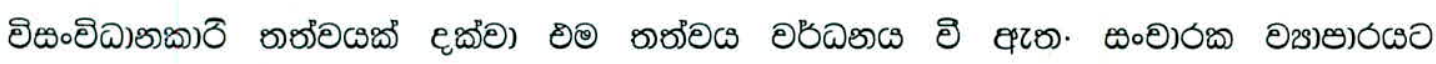

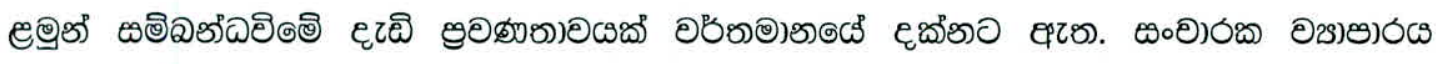

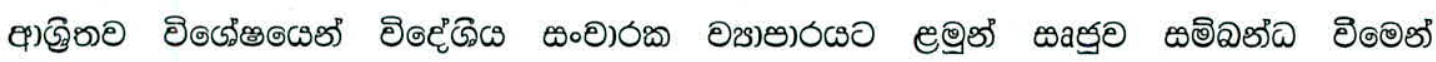

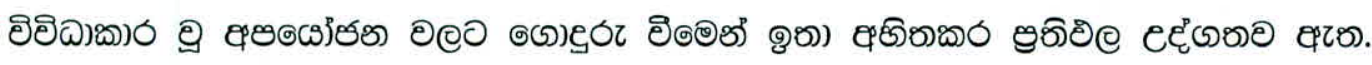

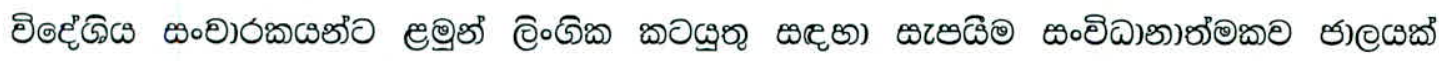

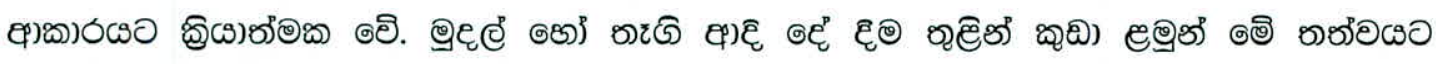

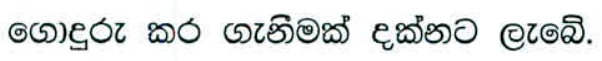

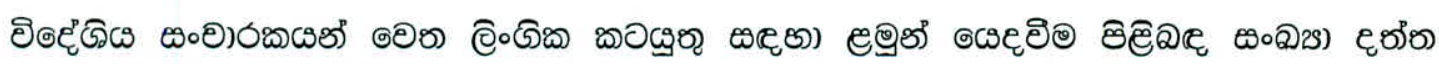

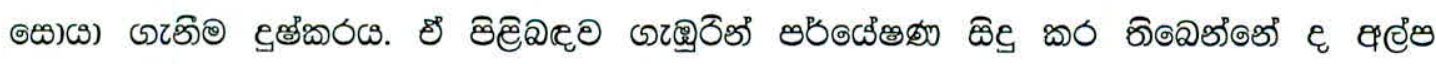
อต๑ตकร). 


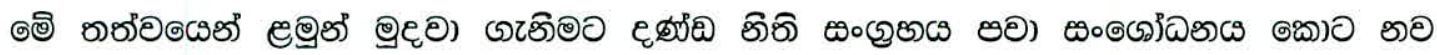

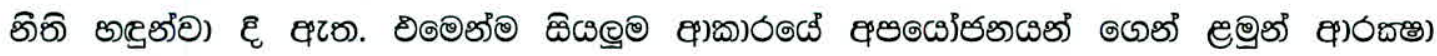

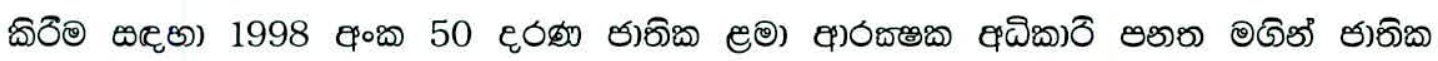

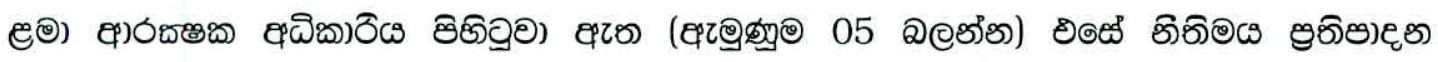

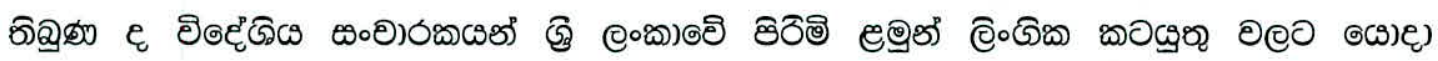

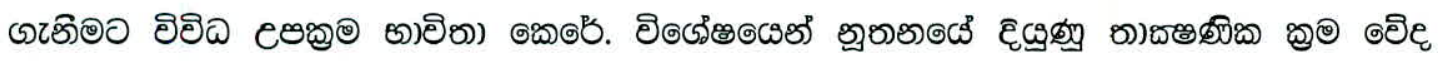

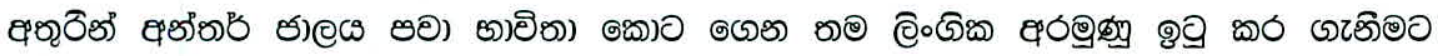

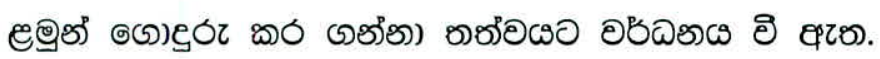

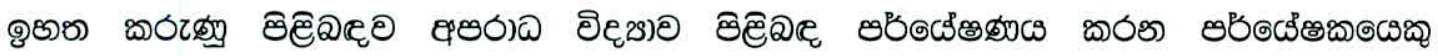

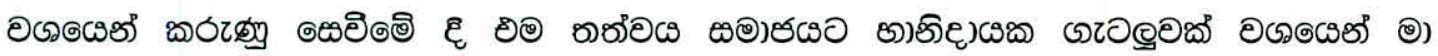

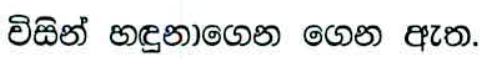

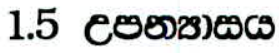

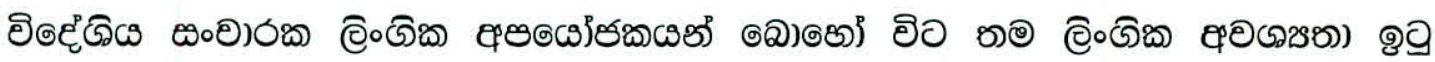

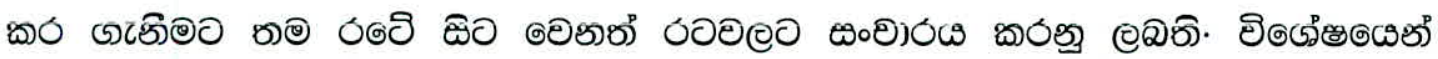

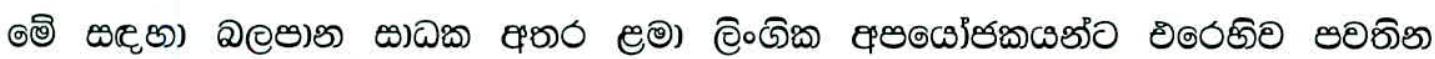

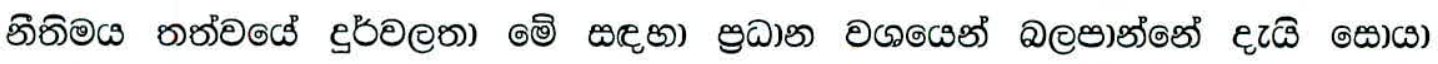

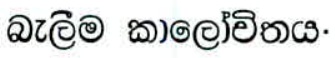

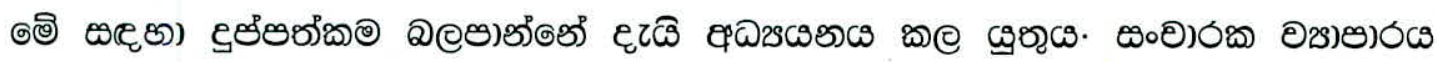

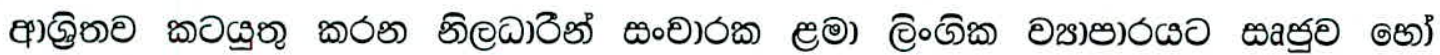

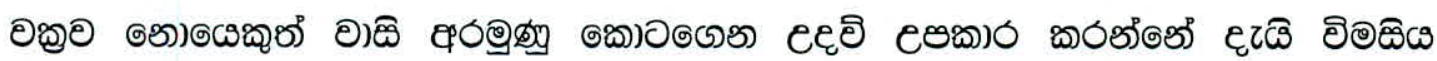

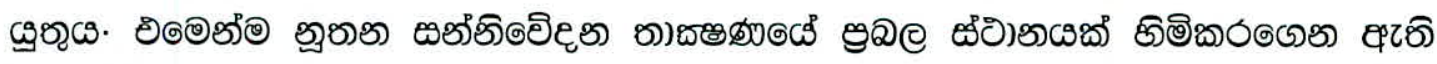

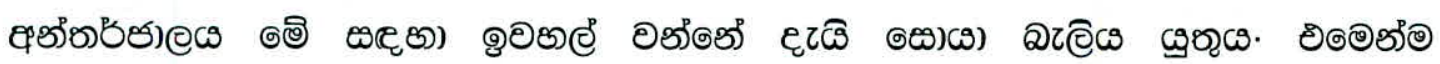

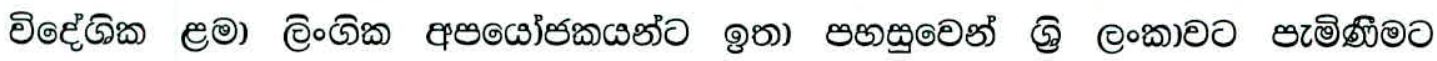

